\title{
PHYSICAL PROPERTIES OF CONCRETE MADE WITH APOLLO 16 LUNAR SOIL SAMPLE
}

\author{
T. D. Lin, H. Love, and D. Stark \\ Construction Tecbnology Laboratories \\ 5420 Old Orchard Road \\ Skokie II 60077
}

$$
\text { N93-1398 }
$$

\section{SUMMARY}

On March 6, 1986, the National Aeronautics and Space Administration (NASA) awarded Construction Technology Laboratories (CTL) $40 \mathrm{~g}$ of lunar soil. The award was made based on a CTL proposal to NASA that lunar soils and rocks could be used as concrete aggregates and as raw materials for manufacturing cement and water. These ingredients could then be used to produce concrete for the construction of lunar bases.

This paper describes the first phase of the long-term investigation for the construction of concrete lunar bases. In this phase, petrographic and scanning electron microscope examinations showed that the morphology and elemental composition of the lunar soil made it suitable for use as a fine aggregate for concrete.

Based on this finding, calcium aluminate cement and distilled water were mixed with the lunar soil to fabricate test specimens. The test specimens consisted of a 1 -in cube, a $1 / 2$-in cube, and three $0.12 \times 0.58 \times 3.15$-in beam specimens. Tests were performed on these specimens to determine compressive strength, modulus of rupture, modulus of elasticity, and thermal coefficient of expansion.

Based on examination of the material and test results, it is concluded that lunar soil can be used as a fine aggregate for concrete.

\section{MATERIALS}

Materials used in the fabrication of the test specimens are described below.

\section{Fine Aggregate}

The lunar soil sample as shown in Fig. 1 and a lunar soil simulant consisting of a glassy rhyolite sand were used as fine aggregates for fabricating test specimens.

\section{Microscopic Analysis of Lunar Sample}

Particles of lunar soil were subangular to subrounded in shape and were somewhat friable. They appeared to have a relatively high porosity. It was estimated that $40-50 \%$ of the sample consisted of white grains, while $50-60 \%$ consisted of grayish black, glassy-appearing grains. The white particles were more friable than the grayish black particles.

In polarized light, the white particles were determined to be wholly crystalline, and consisted of $99 \%$ plagioclase feldspar in the compositional range of bytownite bordering on anorthite. About $80-90 \%$ of this feldspar showed a high degree of undulatory extinction, and about $10-20 \%$ of the feldspar was twinned. Less than $5 \%$ of the plagioclase showed uniform extinction. Traces of glass material, pyroxene, and opaque minerals were also present.

The dark gray to black particles were crystalline, somewhat friable, relatively fine-grained, and subrounded in shape. In polarized light, they were found to consist of about $60-75 \%$ plagioclase feldspar in the compositional range of bytownite bordering on anorthite, and $25-40 \%$ of the particles consisted of minerals in the pyroxene family. Traces of opaque minerals, possibly iron-rich, were also present. Optical characteristics of the feldspar were similar to those of the white particles except that individual crystals were of much smaller size.

Glassy clear particles were present in trace amounts. These particles consisted of individual crystals of plagioclase feldspar in the compositional range of bytownite to anorthite.

\section{Electron Microscopic Analysis of Lunar Sample}

A portion of the lunar sample was analyzed under an ISI-SX 40 scanning electron microscope (SEM) equipped with a Tracer Northern Energy Dispersive X-Ray (EDX) spectrometer system to determine the morphology and elemental composition.

Electron microprobe analysis (EMPA) spectra indicated that the major elements in the sample were $\mathrm{Ca}, \mathrm{Al}$, and $\mathrm{Si}$. Minor elements,

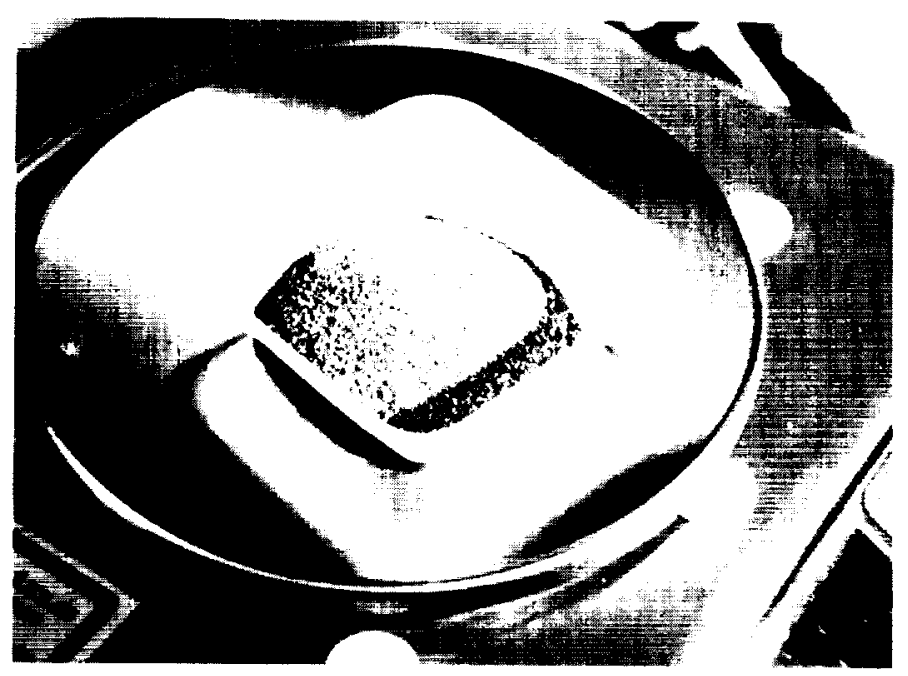

Fig. 1. 40-g graded lunar soil. 
listed in the order of abundance, were $\mathrm{Mg}, \mathrm{Fe},\left(\mathrm{Ka}-\mathrm{K}_{\beta}\right), \mathrm{Ti}, \mathrm{Na}$, and $K$. Many of the particles examined had two good cleavage directions oriented at approximately $90^{\circ}$ to one another. This indicated a crystalline structure.

The 40-g graded lunar soil sample had a similar particle size distribution as the graded Ottawa sand used in the preliminary test program (Lin, 1985a). Table 1 shows the particle size distribution of the lunar soil sample.

In summary, the lunar material analyzed consists primarily of particles of anorthite, a triclinic mineral $\left(\mathrm{CaAl}_{2} \mathrm{Si}_{2} \mathrm{O}_{8}\right)$ with two directions of cleavage $86^{\circ}$ to one another. The measured volume of the $40 \mathrm{~g}$ of lunar soil was $29.2 \mathrm{~cm}^{3}$, the bulk unit weight was $1.37 \mathrm{~g} / \mathrm{cm}^{3}$, the void percentage was $45 \%$, and the specific gravity was $2.5 \mathrm{~g} / \mathrm{cm}^{3}$.

TABIE 1. Particle size distribution of the $40-\mathrm{g}$ lunar soil sample.

\begin{tabular}{lc}
\hline Seive & Retained Weight $(\mathrm{g})$ \\
\hline No. $16(1.18 \mathrm{~mm})$ & 0.0 \\
No. $30(600 \mu \mathrm{m})$ & 1.6 \\
No. $40(425 \mu \mathrm{m})$ & 12.4 \\
No. $50(300 \mu \mathrm{m})$ & 18.0 \\
No. $100(150 \mu \mathrm{m})$ & 8.0 \\
TOTAL & 40.0 \\
\hline
\end{tabular}

$1 \mu \mathrm{m}=10^{\circ} \mathrm{m}$

\section{Lunar Soil Simulant}

Following procedures cited in ASTM (1985, Designation C 13684a), natural Ottawa sand and crushed glassy rhyolite were sieved to produce fine aggregate with the same particle size distributions as the lunar soil shown in Table 1 . The glassy rhyolite is of acid volcanic material that consists of low calcium, high sodium, and high potassium. The material is a highly absorptive, good quality aggregate.

Bulk unit weight of the rhyolite sand was $1.2 \mathrm{~g} / \mathrm{cm}^{3}$, while its specific gravity was $2.34 \mathrm{~g} / \mathrm{cm}^{3}$.

\section{Cement}

Because calcium aluminate cement could be made from lunar materials ( in, 1985b), the commercial calcium aluminate cement was used for the mortar mixes. The specific gravity was $3.08 \mathrm{~g} / \mathrm{cm}^{3}$.

\section{Water}

Distilled water was used for all mixes.

\section{FABRICATION AND CURING OF SPECIMENS}

The following describes the fabrication and curing of the specimens.

\section{Molds}

Three cube molds with $1 / 2^{-}, 1-$, and 2 -in sides were used for casting cube specimens, while a plastic rectangular mold was used to cast the beam specimens.

\section{Mix Proportions}

ASTM Designation C 109-84 (ASTM, 1985) recommends a water-cement ratio of $0.485: 1$ and a sand-cement ratio of 2.75:1 for portland cement used in mortar mixes. No ratios are specified for calcium-aluminate cement. However, to maintain the recommended 0.485:1 water-cement ratio for calcium-aluminate cement and to achieve a suitable workability for the cement, the recommended $2.75: 1$ sand-cement proportion was altered.

The procedure used to select a suitable sand-cement ratio was selected to produce a flow of $110 \pm 5 \%$ as described in section 8.3 of ASTM Designation C 109-84 (ASTM, 1985). Six trial mixes were prepared using highly absorptive glassy rhyolite of the same particle size distribution as that of the lunar soil sample. From these tests proportions of 1.75:1.00:0.485 (sand:cement:water) were selected for the test program.

\section{Fabrication}

The mixing, casting, and curing procedures are presented in Lin et al. (1986).

\section{Determination of Specimen Age for Tests}

During the hydration process, calcium aluminate cement behaves in a substantially different manner than portland cement. The process of hydration is described in Neville (1975). In general, the strength decreases as the duration of water exposure increases. For this reason, 241 -in cubes made with graded Ottawa sand were tested to determine their compressive strengths in relation to specimen ages. The test results show that cubes between three and four days old would give the optimum strength. The $31 / 2$-day age was thus selected for testing the cube specimens.

\section{TEST SPECIMENS}

A 1 -in cube, a $1 / 2$-in cube, and three $0.12 \times 0.59 \times 3.15$-in beam specimens were fabricated from the lunar soil and calcium aluminate cement mortar. In addition to these specimens, 18 companion specimens ( 6 of each kind) were fabricated using the simulated lunar material made with glassy rhyolite and calcium aluminate cement.

\section{COMPRESSION TESTS}

Cube specimens were tested in a compression testing machine. Figure 2 shows a diagrammatic view of the loading portion of the compression machine with a 1 -in-cube specimen positioned

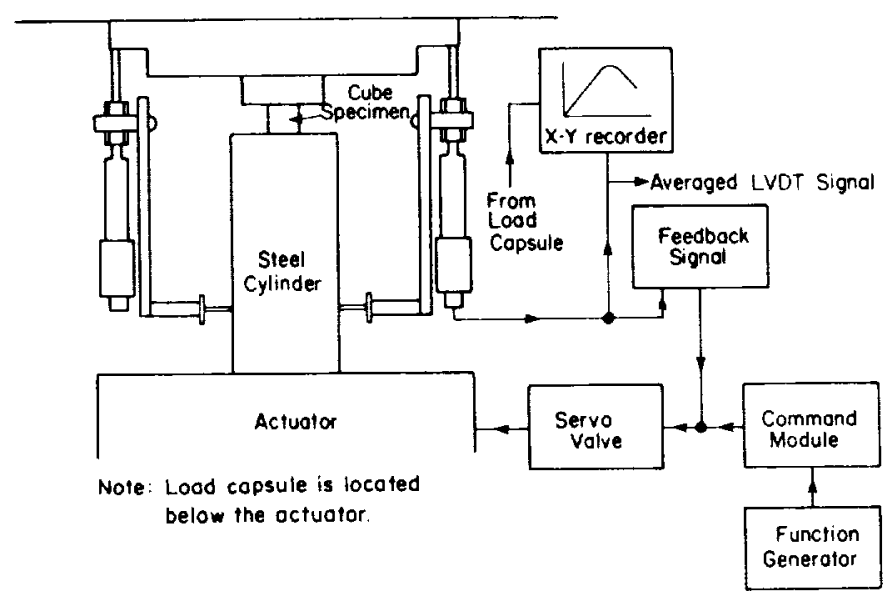

Fig. 2. Closed-loop system of compression test 
below a $3 \times 3 \times 1.5$-in steel plate. The steel plate is secured to the center of the upper bearing block of the closed-loop system.

During the compression test, an input signal is fed into the function generator. The feedback signal is compared with this input signal (in the function generator) by the command module. The difference between the two signals generates a variational signal and the servovalve controls the movement of the platen such that this variational signal is minimized.

Prior to load application, the spherically seated upper bearing block was checked for freedom to tilt. A slight load was applied to ensure full contact between the steel plate bearing block and the test cube. Subsequently the bearing block was fixed and the load was applied slowly to follow the programmed deflection control curve. The rate of loading was controlled to produce a cube contraction of approximately $10 \mu \mathrm{in} / \mathrm{sec}$. In general, the test load reached a maximum in $20 \mathrm{~min}$ and then slowly decreased. Each compression test was completed in about $45 \mathrm{~min}$.

Figure 3 shows the stress-strain curve for a cube made with the lunar soil sample and for a representative companion cube made with the highly absorptive rhyolite simulant obtained during the compression tests. Compressive strength for the lunar cube was $10,970 \mathrm{psi}$. The average compressive strength of the companion cubes was 7960 psi.

Static moduli of elasticity were estimated to be 1.8 million psi for the lunar cube and 1.1 million psi for the cubes made with the rhyolite. These values were calculated by taking the steepest slope of the rising portion of the stress-strain curve shown in Fig. 3.

The longitudinal and lateral deformations of test cubes under the compressive load were recorded manually. From these data, Poisson's ratios were calculated. Calculations were made up to the peak load of each test. No lateral deformations were observed in the cube made with the lunar soil for stresses below $6600 \mathrm{psi}$. The cube made with rhyolite did not show any appreciable lateral deformation until a stress of 4800 psi was reached. Figure 4 shows calculated Poisson's ratios of both types of cubes in graphical form. At peak load, Poisson's ratio was 0.39 for the lunar soil mix and 0.27 for the rhyolite mix.

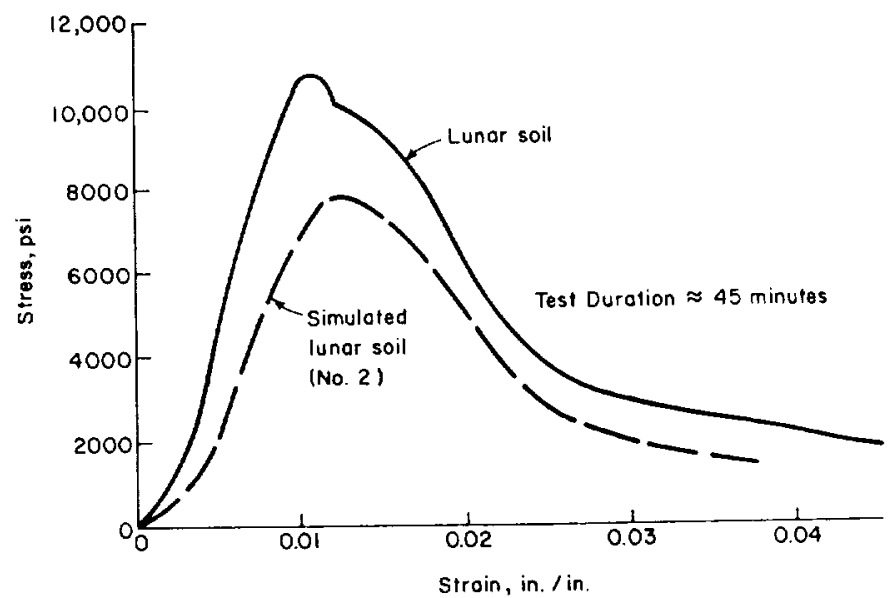

Fig. 3. Measure stress-strain curves

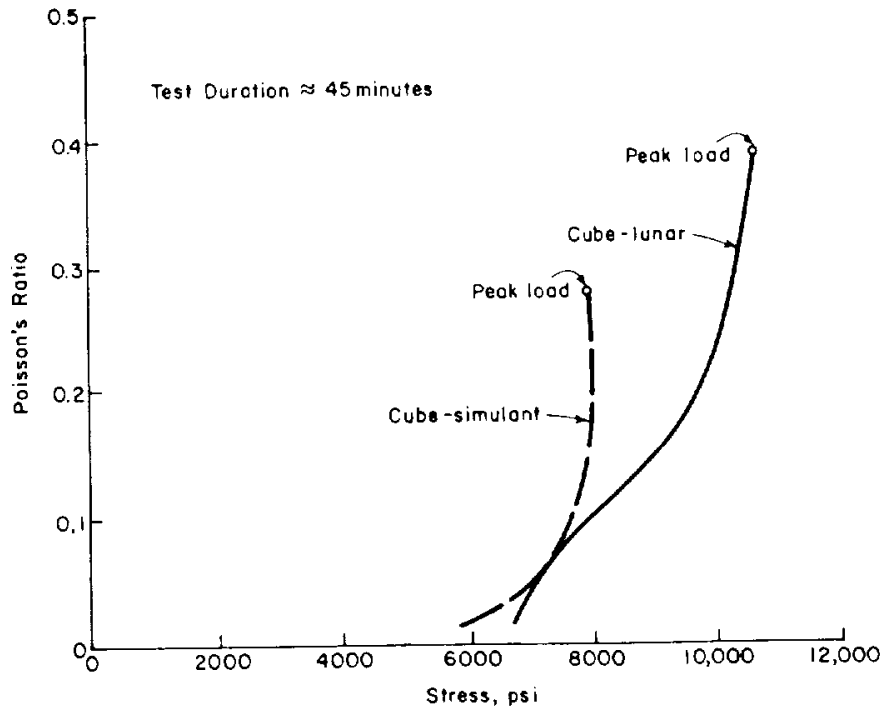

Fig. 4. Poisson's ratio of cubes made with lunar soil and simulated lunar soil.

\section{MODULUS OF RUPTURE}

One beam made with the lunar soil mix and three beams made with the rhyolite mix were tested using an Instron testing machine to determine flexural strength. Figure 5 shows a diagrammatic view of the flexural test set-up. Each beam specimen was subjected to two concentric loads at the third points of the span.

The section modulus, $Z$, of each beam was calculated from its geometric properties. Maximum bending moment was calculated using the equation

$$
M=\frac{P L}{6}
$$

where $P$ is the maximum load at rupture and $L$ is the span length between supports. In this case, L was 3.06 in $(78 \mathrm{~mm})$. The modulus of rupture was obtained by dividing $\mathrm{M}$ by $\mathrm{Z}$. The average moduli of rupture for beams made with simulated lunar material was $1244 \mathrm{psi}$, while that of the beam made with the lunar material was 1206 psi.

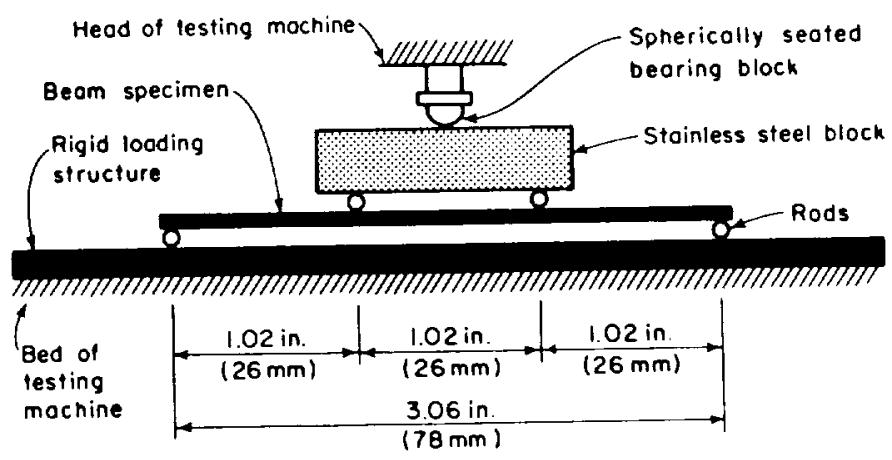

Fig. 5. Diagrammatic view of flexural test set-up. 


\section{DYNAMIC MODULUS OF ELASTICITY}

The dynamic modulus of elasticity of the hardened mortar was determined with a sonometer. Measurements of the fundamental flexural resonance frequencies of beam specimens were made in a glove box to ensure a $\mathrm{CO}_{2}$-free atmosphere, a controlled relative humidity, and a temperature of $75^{\circ} \mathrm{F}$.

The beam was supported near a node and vibrated by a wire clip driven by a crystal phonograph cartridge. The other end of the specimen was supported at a node by a soft foam plastic pad. Vibration was detected by a wire probe cemented to a Sonotone $3 \mathrm{P}$ - $1 \mathrm{~S}$ ceramic cartridge. The cartridge was mounted in a modified Rek-o-Cut S-320 tone arm. Stylus pressure was adjusted to the minimum required to maintain contact between the specimen and probe. The arrangement is shown in Fig. 6. Dynamic modulus of elasticity for the beam made with lunar soil mix was 3.12 million psi, while the average modulus of elasticity for the beams made with the rhyolite mix was 2.81 million psi.

It is not uncommon that the modulus of elasticity obtained by the resonant method is higher than that obtained by the static method. This is due to the fact that in the static procedure, the cube under sustained load experiences creep. The creep strains add to the total elastic-plastic deformation resulting in a lower modulus of elasticity.

\section{THERMAL EXPANSION COEFFICIENTS}

Figure 7 shows the test set-up of a commercially manufactured dilatometer and a heating/cooling unit for measuring thermal expansion of beam specimens.

Thermally induced deformations of the specimens were transferred through a fused silica rod attached to an Invar bar that rode on ball-bearing pulleys. The end of the Invar bar rested against the plunger of a dial gauge with a calibrated sensitivity of $0.002 \mathrm{~mm}$. Pressure from the light spring of the dial gauge kept the specimen in contact with the closed end of the fused silica tube.

The core of a linear variabie differential transformer (LVDT) was mounted axially on the outer end of the dial gauge plunger. Housings for the dial gauge and LVDT were mounted on an adjustable assembly fixed to the slate base. In addition to lightly loading the specimen, the dial gauge was also used to calibrate the response of the LVDT.

Length changes measured by the LVDT included a component caused by thermal expansion of the fused silica tube and rod used to contain the specimen. Expansion of the fused silica components was approximately $2-7 \%$ of the length changes of the specimen. Data were corrected for this effect using results of calibration tests on fused silica specimens (Cruz and Gillen, 1980).

Thermal expansion of the specimen measured by the LVDT and specimen temperature measured by thermocouples were continuously recorded on an X-Y plotter. Each specimen was subjected to heating and cooling for 2 complete cycles to determine its response to temperature changes that varied from $-100^{\circ}$ to $350^{\circ} \mathrm{F}$.

Measured data were used in calculating coefficients of thermal expansion at elevated temperatures as well as low temperatures. A $5 \%$ correction was made for each computed value to compensate for the thermal expansion of the fused silica rod. The average thermal expansion coefficient for beams made with lunar sample was 2.9 millionth in $/$ in $/ F$, while the average thermal expansion coefficient for beams made with rhyolite mix was 3.5 millionth in $/$ in $/ F$

\section{URIGINAL PAOE \\ BLACK AND WHITE PIHOTOGRAPH}

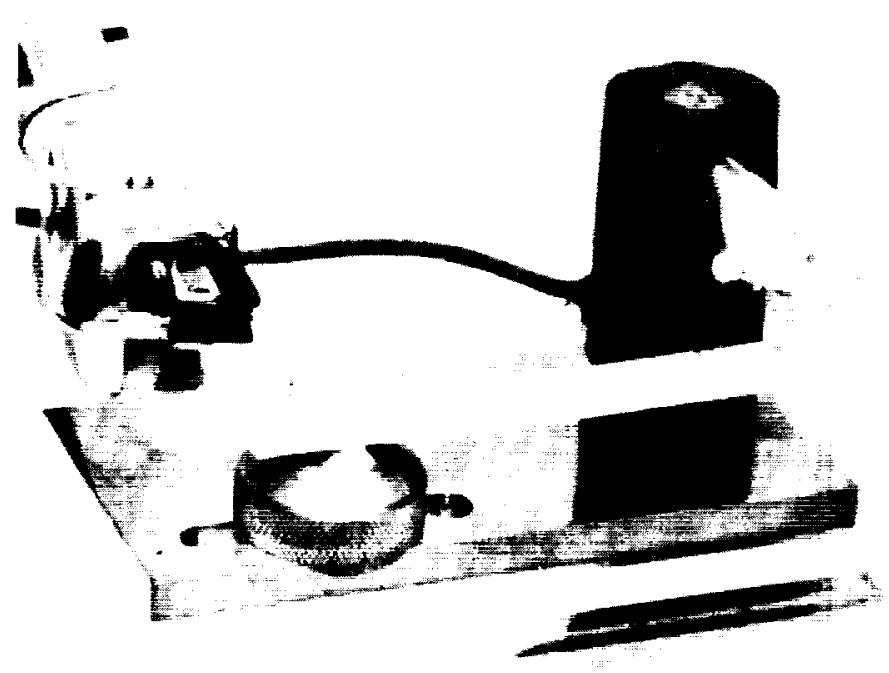

Fig. 6. Measurement of fundamental flexural resonance frequencies.

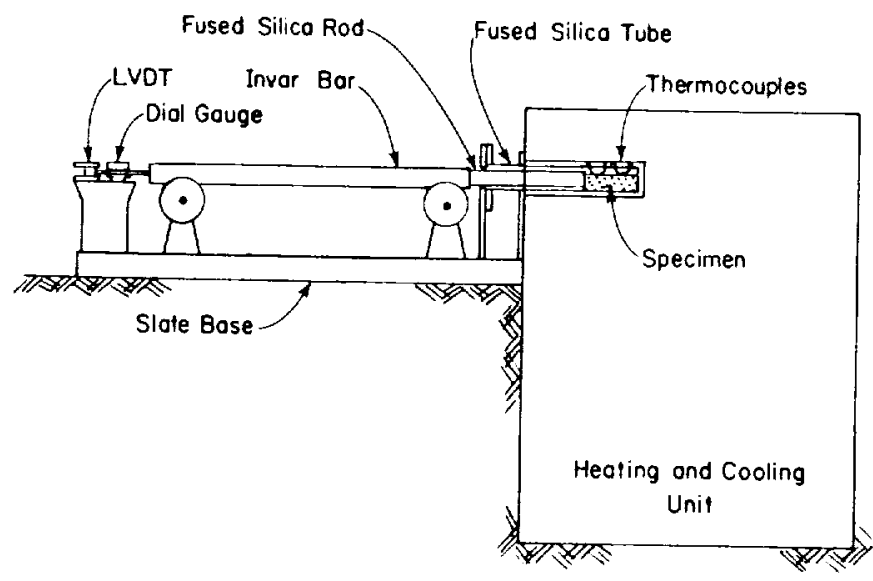

Fig. 7. Commercially manufactured dilatometer.

\section{EXAMINATION OF LUNAR CUBE AFTER TEST}

Following the determination of compressive strength, the tested 1-in cube was examined microscopically to characterize the microstructure of the mortar. A stereomicroscope with a magnification range from 7 to 35 was used for this work.

Microscopic examination revealed that the calcium aluminate cement paste matrix was light brown in color and contained a uniform distribution of entrapped air voids. The estimated amount of air voids was $8 \%$ by volume of mortar. The paste matrix displayed a uniform intimate bond with the aggregate particle. Esentially, there were no entrapped air voids in direct contact with the particles.

The examination also revealed that fractures that developed during compression testing almost invariably passed through aggregate particles. Only in a few cases did cracks pass around the particles at the paste-aggregate interfaces. In addition, virtually 
no aggregate sockets were visible on fractured surfaces. This further attests to the tendency of cracks formed during the compression test to pass through the aggregate particles.

\section{ANALYSIS OF RESULTS}

Mechanical properties of the lunar soil are governed by the distribution of grain sizes, the angularity of the grains and its porosity. The lunar soil sample had particle sizes ranging from about 0.1 to $0.8 \mathrm{~mm}$. Particles were either subangular or subrounded in shape. It should be noted that particle shape and surface texture have a greater influence on properties of fresh concrete than on properties of hardened concrete. Roughtextured, angular, elongated particles require more water to produce a workable mix than do smooth, rounded, compacted aggregates. This means that the use of lunar soil as aggregate for a concrete mix will require more water than terrestrial sand does.

The bond between cement paste and a given aggregate generally increases as particles change from smooth and rounded to rough and angular. This increase in bond is a consideration in selecting aggregates for concrete where either high flexural strength or high compressive strength is needed. Test data revealed that the lunar soil has suitable physical properties for use as a fine aggregate.

For aggregate of the same grading, the water requirement for mixing tends to increase as aggregate void content increases. The lunar soil is dry and has $45 \%$ void content, $5 \%$ higher than that of graded Ottawa silica sand. Again, the lunar soil tends to require more water to produce workable concrete than the smooth, rounded Ottawa sand.

An examination of the lunar soil sample using the SEM revealed that lunar soil includes breccia, lithic grains, mineral grains, glass fragments, and lunar agglutinates. Some grains developed microfractures due to impact of micrometeorites. The immediate concern for use of lunar soil in making concrete was the effect of agglutination and microfractures on concrete strength.

Careful examination of expanded shale lightweight aggregates commonly used in construction today shows that a greater percentage of the material is composed of agglutinates formed during the sintering process at temperatures ranging from 1800 to $2220^{\circ} \mathrm{F}$. It appears that the agglutinated joints often develop strength higher than the strength of the expanded shale itself.

Test results of the cube specimen made with the lunar soil sample and examination of the tested cube provide convincing evidence that the agglutination and microfractures caused no negative effect on the cube strength.

Mature lunar soil consists of about $110 \mathrm{ppm}$ solar-wind $\mathrm{H}$ and noble gases such as $\mathrm{Ar}$ and $\mathrm{He}$ (Morris, 1983). It is believed that the gas-rich surface of soil particles has no drawback on the cube strength; on the contrary, it may improve the quality of concrete.
For example, the use of admixtures will help explain this phenomenon. In the process of making concrete, air-entraining agents are often used to create air bubbles and thus to increase the durability of the concrete. This demonstrates that $N$, about $78 \%$ in air, has no negative effect on the strength of concrete. Argon and $\mathrm{He}$, like $\mathrm{N}$, are inert gases and are believed to have no effect on cement hydration.

\section{CONCLUSION}

Forty grams of lunar soil were evaluated to determine if the material was suitable as fine aggregate for making mortar specimens. Examination by optical microscope showed that angularity of the particles would be likely to cause lunar concrete mixes to require more mixing water than well-rounded terrestrial sands. However, the observed angularity of lunar soil particles would tend to increase the bond between cement paste and aggregate, thereby providing increased strength when compared with well-rounded sands. Slightly higher water requirements would also result from the higher void content and dry conditions observed for lunar soil.

Scanning electron microscope examination showed agglutination and microfractures similar to those found in manufactured lightweight aggregates, and the results of cube tests provide convincing evidence that no negative effects are caused by the agglutination and microfractures. Similarly, the gas-rich surface of lunar soil particles should improve the quality of concrete or have no effect. Finally, the data obtained provide scientific evidence that lunar soil can be used to produce quality concrete for construction on the Moon or in space.

Acknowledgments. The authors would like to express their gratitude to NASA for awarding the $40 \mathrm{~g}$ of graded lunar soil collected during the Apollo 16 mission.

\section{REFERENCES}

ASTM (1985) Annual Book of ASTM Standards. American Society for Testing and Materials, Philadelphia.

Cruz C. R and Gillen M. (1980) Thermal Expansion of Ptrtland Cement Paste, Mortar, and Comcrete at High Temperatures. PCA Publication RD074.01T.

Lin T. D. (1985a) Testing Concrete Specimens Made uth Lunar Soil. Report to NASA.

Lin T. D. (1985b) Concrete for lunar base construction. In Lunar Bases and Space Actitities of the 21st Century (W. W. Mendell, ed. ), pp. 381 390. Lunar and Planetary Institute, Houston.

Lin T. D., Love H., and Stark D. (1986) Testing Concnete Secimens Made with Lunar Soil. Report to NASA.

Morris R. V. (1983) Handbook of Lumar Soils. Parts I and II. NASA Planctary Materials Branch, Publication 67

Neville A. (1975) High Alumina Cement Concrete. Wiley, New York. 
